\title{
Poder político y "bárbaros" en Chihuahua hacia 1845
}

Luis Aboites Aguilar CIESAS

El autor estudia la respuesta de la población chihuahuense a la persistente incursión de indios nómadas en su territorio.

A

1 inicio de la década $1840-50$ el norte del paísse veía amenazado de porelexpansionismo floreciente como por los ataques intermitentes de distintos grupos de indígenas nómadas. El problema indio mostraba nuevasfacetas. Una de las más importantes era precisamente la creciente presencia de los estadunidenses en la vida del antiguo septentrión novohispano. ${ }^{1} \mathrm{El}$ comercio a través de Santa Fe y la guerra y subsiguiente separación de Texas constituían elementos que contribuían a con-

${ }^{1}$ Vázquez y Meyer, México, 1989, pp. 51-54; Weber, La frontera, 1988, p. 143. figuraruna situación en la que losataques de apaches y comanches adquirían mayor vigor y complejidad. El intercambio entre nómadas y comerciantes estadunidenses (y mexicanos también) abría una alternativa económica más estable para la multiplicación de la beligerancia india. El intercambio de armas por ganado robado parecía ser uno de los ejes de ese comercio, según denunciaría años después una comisión oficial mexicana. ${ }^{2}$

${ }^{2}$ La comisión también involucraba al gobierno del vecino pais: "El gobiemo americano tolero, disimuló y puede sostenerse que protegió y favoreció aquellas depredaciones. Los comanches y apaches jamás se empeñaron en la comisión de males, con la persistencia que se notó desde 1836; esto es, desde que por medio de sus oficiales les 


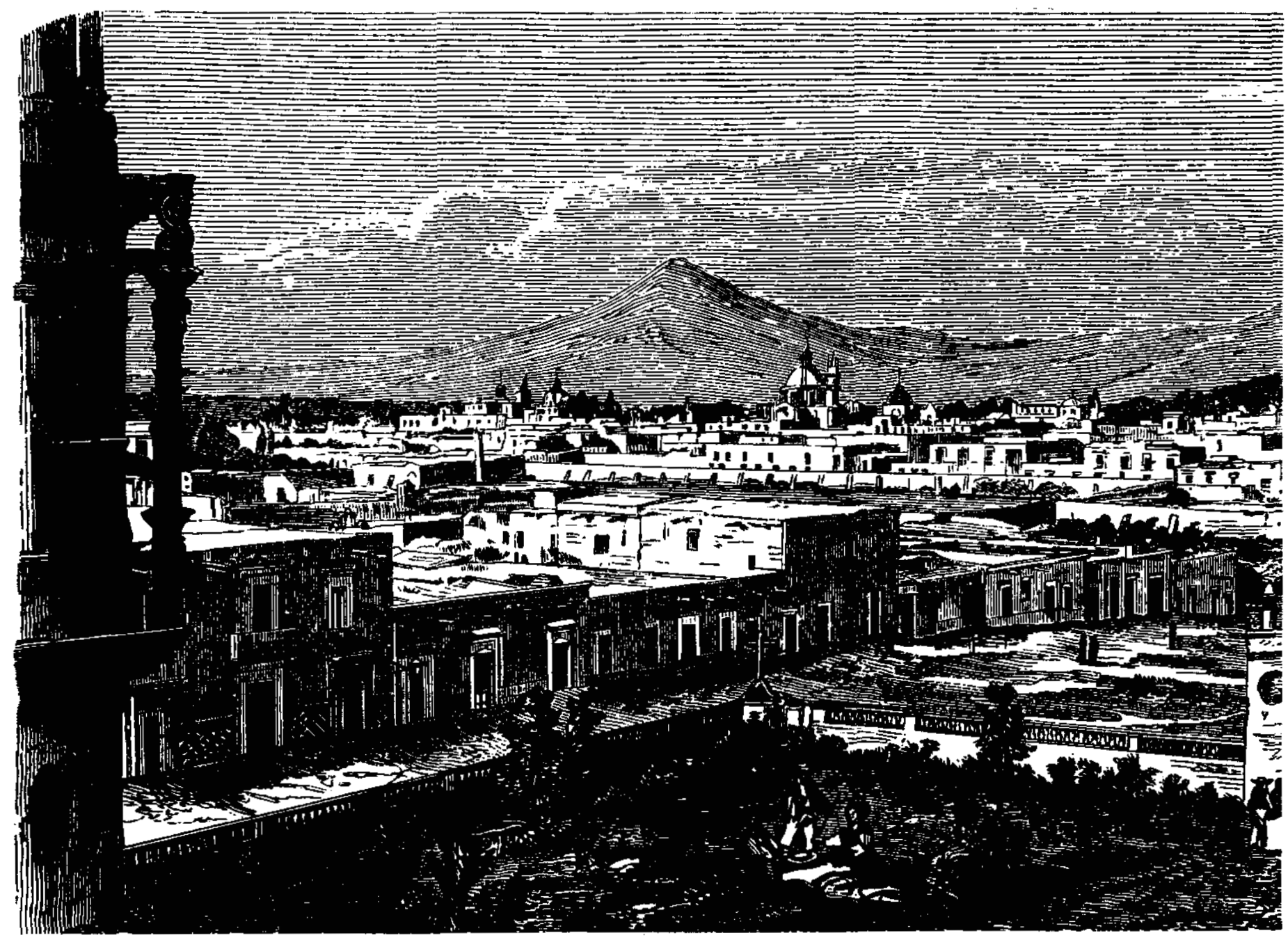

Los pobladores de las entonces jurisdicciones departamentales del septentrión hallaban grandes dificultades para enfrentar la amenaza de los nómadas. No es que paralizaran sus actividades económicas, pero sí tenían que ver cómo extinguir o por lo menos aminorar ese punzante golpeo que les significaba pérdidas económicas y de vidasy queademás dificultaba la expansión del poblamiento y de la explotación de recursos y rutas comerciales.

En este trabajo se intenta ahondar en las formas de respuesta de los pobladores chihuahuenses a la amenaza nómada, destacando las limitaciones del aparato gubernamental para encabezar, organizar y centralizar esa respuesta

abrio un mercado bien provisto para cambiar con ellos los robos que hacían en México", Informe, 1877 , p. 18. militar y política. Al reparar en esas limitaciones se pretende explorar otros aspectos de un fenómeno más amplio y complejo quetienequever con el carácter del Estado en esa época, especialmente en términos de su precario control efectivo sobre el territorio y la naturaleza de su relación con los distintos grupos sociales. La idea es ensayar una aproximación interpretativa que ayude a facilitar el acceso al abundante material que existe sobre esta temática en un periodo muy poco estudiado como es el de los años de la década de 1840.

\section{LA FRAGILIDAD ANTE LOS BÁRBAROS}

Uno de los primeros rasgos que sobresale del material disponible es que la amenaza nómada ponía en evidencia la fragilidad del aparato estatal. Ese rasgo 


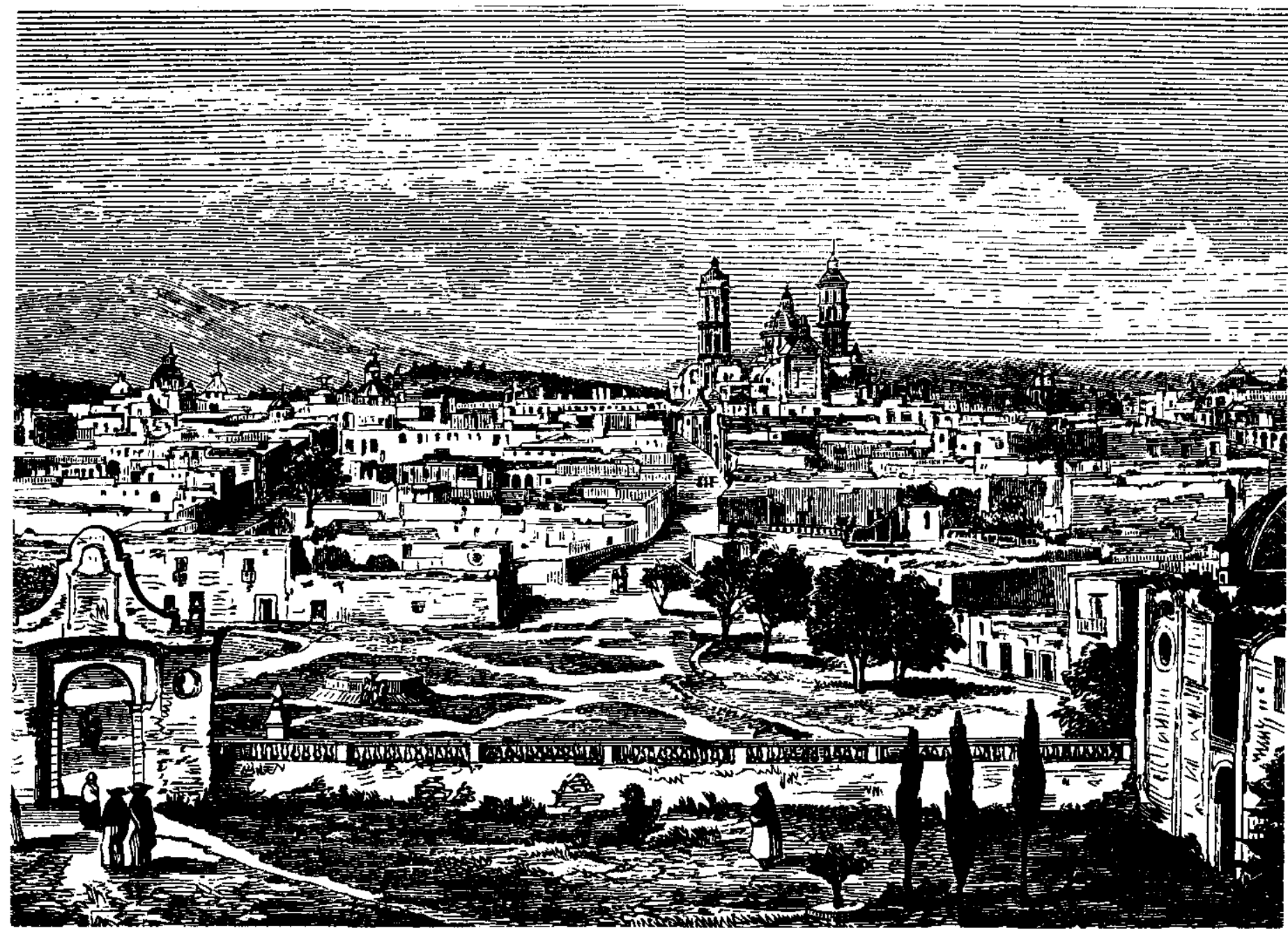

no solamente se refería a la escasez de sus recursos presupuestales, cosa que al lector versado en este periodo no debe sorprender. Además, la fragilidad tenía que ver con la insuficiente fuerza del ejército, o de la fuerza represiva pública. Sin que esta afirmación lleve a minimizar el papel del ejército en la vida local, resulta evidente que la debilidad de la fuerza militar abría las condiciones para una intensa participación de los particulares en las acciones ofensivas y de defensa. Ello se traducía en una borrosa delimitación de las esferas pública y privada en esta materia. La tendencia, sin embargo, apunta hacia la recuperación del poder público en la salvaguarda de la tranquilidad pública, es decir, una de las funciones primordiales de toda organización política institucionalizada. ${ }^{3}$

${ }^{3}$ Se dice "recuperación" para señalar el hecho
A mediados de 1842 el general Francisco García Conde daba a conocer un largo informe sobre su actuación como comandante general de Chihuahua y como gobernador del departamento en ocasión de su visita a El Paso y Janos. ${ }^{4}$ Este general, miembro de una familia sonorense que daría varios militares distinguidos, había arribado a Chihuahua a principios de 1840 como jefe militar. Poco después los chihuahuenses lo

de que a fines del siglo xvil el Estado colonial habia logrado avances significativos en la pacificación del septentrión.

${ }^{4}$ Este informe, titulado "Manifiesto que dirige a los habitantes del Departamento de Chihuahua el C...", de 18 de agosto de 1842 , fue publicado por el Diario del Gobiemo de la República Mexicana, el 23 de septiembre de 1842 . Se halla en el volumen 394 de la Colección Lafragua. Recientemente fue reproducido por Altamirano y Villa en Cbibuabua, 1988, t. III, pp. 797-818. 
propondrían como gobernador, cosa que el presidente de la república había aceptado. Una de sus primeras medidas había sido la de cancelar el contrato con Santiago Kirker, el famoso cazador de cabelleras de indios. ${ }^{5}$

Abría su informe señalando que en 1840 se cumplían nueve años de guerra contra los apaches y la caracterizaba "como mil veces peor que la extranjera, más funesta que la civil" ${ }^{6}$ Después ofrecía un marco de referencia:

El gobiemo general, ocupado con la [guerra] de Francia, con las convulsiones interiores, yempobrecido a consecuencia de éstas y de aquélla, había de hecho abandonado la suerte de Chihuahua a sus propios recursos que estaban agotados, y a los esfuerzos de sus habitantes que apenas podían sostenerse...

El esfuerzo de los chihuahuenses no había sido muy efectivo, según afirmaba el militar:

Hombres eminentemente patriotas y de grandes concepciones, habían luchado en este periodo con la desgracia, ensayando varios planes de agresión y de defensa. Cualquiera de ellos, sostenido y llevado a cabo, hubiera surtido sus efectos; pero como la guerra se mantenía en gran parte a expensas de los particulares, y sus consecuencias afectaban a cada uno de los individuos, la autoridad tenía que ceder muchas veces; sus planes se desacredita-

${ }^{5}$ Almada, Diccionario, s. f., p. 302. Kirker había sido contratado en diciembre de 1839 para combatir a los apaches durante cuatro meses, con una partida de 200 hombres. Para pagar ese contrato el gobierno recurrió a una contribución extraordinaria de 100000 pesos; también redujo sueldos de burócratas.

${ }^{6}$ Sobre daños y reclamos chihuahuenses en virtud de los ataques nómadas en el periodo 18311837 puede verse la obra de Ponce de León, Reseña, 1905, pp. 161-162. ban cuando apenas habían tenido tiempo para producir inconvenientes y no ventajas: sucedian a éstos otros que no corrían mejor suerte; la confusión crecía con la miseria; los ciudadanos se desalentaban; $y$ sin que nadie pudiera sustituirlo, se desprestigiaba el poder público.

Por lo menos pueden subrayarse dos aspectos. El primero se refiere al "desprestigio" del poder público, el cual parecía surgir de su incapacidad para trazar por lo menos una estrategia militar consistente. El otro aspecto tiene que ver con la afirmación de que "la guerra se mantenía en gran parte a expensas de los particulares" y a que "la autoridad tenía que ceder muchas veces". ${ }^{7}$ Puede pensarse que, la pobreza del erario público, traducida en una cotidiana dependencia de los recursos de los particulares, dificultaba la consolidación del aparato gubernamental. El problema era, como lo señala el propio García Conde, que nadie podía sustituir al poder público.

El funcionario señalaba que se había visto precisado a solicitar donativos a los habitantes del departamento por medio de las circulares de 8 y 9 de enero de 1841: "Los resultados fueron tan felices que en el solo distrito de la capital importaron los donativos más de 5000 pesos

\footnotetext{
${ }^{7}$ Años más tarde el gobernador del Departamento diría sobre la guerra contra los apaches: "El remedio de tan grave mal era el objeto que ocupaba la atención de sus autoridades; mas nilos desvelos de éstas, ni los esfuerzos que se hacían por los particulares más acomodados, llenaban las esperanzas de los chihuahuenses." Archivo General de la Nación, Gobernación, 1845, sin sección, caja 283, expediente 8: carta de 16 de abril de 1845 de Luis Zuloaga al ministro de Relaciones. En adelante las referencias a este archivo serán AGN, seguido del año, el número de la caja, el del expediente y el documento. Ello porque la información de este archivo proviene del lugar señalado en esta nota.
} 
por trimestre." ${ }^{18}$ Sin embargo, estos esfuerzos, destinados a resolver el problema con los apaches, se vieron alterados por la primera incursión de texanos en Nuevo México en el otoño de 1841. "Las fuerzas preparadas contra los apaches -apunta García Conde-, tuvieron que acudir a donde amenazaban los texanos". Este incidente obligó a posponer hasta 1842 el arreglo con los nómadas.

Durante la primera mitad de ese año García Conde logró establecer convenios de paz con grupos de apaches gileños y mezcaleros, convenios que acarreaban un gasto mensual de 4000 a 5000 pesos. El militar, no sin recordàr que los españoles habían tenido éxito con ese tipo de convenios (aun sin contar "...hoy con los recursos pecuniarios que se tenían entonces"), explicaba:

¿Qué valen 405000 pesos cada mes comparados con los enormes gastos de la guerra y con las incalculables pérdidas que ella origina? 'Nodaríamos los 700000 que ellas hubieran costado en los once años de hostilidades, por los millones que importan las propiedades destruidas y lo que éstas hubieran producido?

Las peticiones de dinero a los vecinos del departamento se repetirían en los meses subsiguientes. En marzo de 1843

${ }^{8}$ Esta petición se hizo necesaria no obstante que el gobierno general le había proporcionado dinero en efectivo, proveniente de la aduana de Mazatlán, al parecer 5000 pesos durante cuatro o seis meses. Del mismo modo, el gobierno general había concedido permiso para recaudar el octavo que se cobraba de más en cada cigarro. Sin embargo, la recaudación de principios de 1841 se vio obstruida por la ley de 8 de marzo de ese año que estableció una contribución personal en toda la república. Del gobiemo general García Conde también recibió monturas y 600 caballos, que recogió en León y Durango. Almada, Gobernadores, 1950, p. 92. el gobernador José Mariano Monterde informaba que por la escasez de la renta de tabacos había tenido que "interponer mis respetos personales con algunos acomodados de la capital de este departamento para un préstamo de 10000 pesos". Con ese dinero el gobernador pudo viajar a los presidios del norte a celebrar diversos tratados de paz con diversas partidas de indios, entre ellos con los gileños. ${ }^{9}$

Lo mismo ocurrió en ocasión de la segunda incursión texana a Nuevo México de mediados de 1843. El comandante militar y gobernador, general Monterde, se vio obligado a solicitar un préstamo de 12000 pesos para preparar la fuerza que acudiría en auxilio de esa provincia norteña. ${ }^{10}$

Uno de los vecinos más ricos de Chihuahua en esos años, el comerciante JoséCordero, recordaria en 1852 que "en los últimos 20 años" había aportado más de 200000 pesos en préstamos al gobierno, la mayor parte sin cobrar intereses. ${ }^{11}$ Es muy probable que Cordero fuera uno de los prestamistas más importantes del gobierno local, pues en noviembre de 1852 un grupo de diputados locales lo llamaba "agiotista escandaloso"

\footnotetext{
${ }^{9} \mathrm{AGN}, 1843,265,5$ : carta de Monterde del 24 de marzo de 1843,al ministro de Relaciones enviada desde Casas Grandes. Monterde menciona cinco presidios en el departamento: San Buenaventura, Janos, San Elizario, Carrizal y Frontera de Paso del Norte.

${ }^{10}$ Almada, Gobernadores, 1950, p. 92.

${ }^{11}$ El Siglo $X L X, 22$ de agosto de 1852. Ver el "Manifiesto" suscrito por Cordero, entonces gobernador de Chihuahua. Alli mismo Cordero afirma que se le acusa de "déspota especulador". Sin embargo, en agosto de 1842 García Conde lo calificaba de "patriota". En 1858 la fortuna de Cordero se estimaba en 800000 pesos. Lorenzo ArellanoS., "Las grandes fortunas en 1858", en El Heraldo de Cbibuabua, 18 de agosto de 1940 .
} 
ylo acusaban precisamente de lucrar con el erario público. ${ }^{12}$

El gobierno local requería de otro tipo de colaboración privada para llegar a arreglos con los a paches. Por ejemplo en 1843 el gobernador Monterde convocó a los "vecinos más notables y acomodados" del presidio de San Buenaventura con el fin de obtener en préstamo algunas extensiones de tierra cultivable para el uso de los apaches pacificados que se asentarían en ese lugar. Además de favorecer la tranquilidad pública, el establecimiento de los indios y su conversión en agricultores tenía también una razón presupuestal:

Si afortunadamente consigo -decía Monterde-que los bárbaros a quienes prestaré todos los [ielementos?] necesarios para la labranza se dediquen a este trabajo, no dudo en afirmar que el erario público dejará de hacer los precisos gastos que por aquel objeto [su manutención] hoy gravitan sobre él, como en tiempos del gobierno español gravitó por algunos años. ${ }^{13}$

Los gobernantes locales se veían obligados a requerir de otra manera los recursos de los vecinos. El notablemente populargobierno de García Conde había recurrido a la formación de milicias en varios pueblos del departamento, según informaba en su "Manifiesto" de agosto de 1842. Con ello se esperaba mejorar la capacidad de respuesta ante los ataques de apaches. Este recurso, que había sido utilizado por lo menos desde tiempos de Teodoro de Croix, estaba vedado sin embargo para los regímenes con escaso respaldo político. Ese sería el caso de los

${ }^{12}$ Ver el remitido de los diputados en El Siglo $X I X, 18$ de noviembre de 1852 .

${ }_{13}$ Ver la carta de Monterde ya citada, de marzo de 1843. gobernadores Monterde y Luis Zuloaga, sucesores de García Conde.

No extraña, por esa razón, que Zuloaga insistiera en la necesidad de mejorar y aumentar los presidios:

En diferentes épocas se creía que armando a los pueblos se conseguirían grandes ventajas contra el salvaje; pero ni este medio, ni los proyectos de gratificación que entonces se establecieron por la muerte de cada uno de los apaches, ni fiarse a manos extrañas la defensa como sucedió formalizándose la campaña... al mando del extranjero don Santiago Kirker, fueron suficientes para conseguir el escarmiento de los agresores, perdiéndose con vanas ilusiones el tiempo, el dinero que se gastaba en esas expediciones sin el más pequeño fruto, y dispersándose los de las fuerzas presidiales que pudieran haber obrado con algún provecho si se hubieran dirigido a la sombra de las providencias tan bien combinadas como las que el gobierno español nos legó en tantos documentos que ministran los que existen en los archivos de esa época..$^{14}$

Puede pensarse que un gobierno impopular temía la existencia de cuerpos de civiles armados porque significaba una amenaza para el propio gobierno. Por el contrario, un régimen popular podía ayudarse de esas fuerzas sin temor. Los acontecimientos chihuahuenses subsiguientes parecen convalidar esta forma de acercamiento.

Después del éxito del movimiento militar contra el gobernador Zuloaga en

${ }^{14}$ AGN, 1845, 283, 8: Carta de Luis Zuloaga de 18 de abril de 1845 al ministro de Relaciones. Ver también en este lugar la carta de Zuloaga de 29 de marzo de 1845 en la que propone un sistema de dos líneas de presidios para la defensa contra comanches: la primera de 150 hombres sobre el río Bravoy la segunda de 100 hombres entre Coyame, Aldama, Santa Rosalía y San Pablo. 
junio de 1845 , que será tratado más adelante, Angel Trías asumiría por primera vez la gubernatura con gran apoyo delos chihuahuenses. En un decreto de 3 de octubre de ese año se ordenaba la formación de batallones denominados "defensores del departamento contra los indios bárbaros". El texto de las consideraciones es por demás revelador:

La Asamblea Departamental, considerando: 1. Que desde el año anterior han tomado incremento las incursiones de las tribus apaches y comanches; 2 . Que cada día es más cruel y devastadora la guerra que hacen en lo interior del departamento, y que este mal acabará con su población y riqueza, si no se trata de atajarlo desde luego con esfuerzos extraordinarios; 3 . Que las compañías presidiales no pueden llevar enteramente este objeto por hallarse situadas en las fronteras para la defensa exterior; 4. Que debiendo ocuparse de la interior los mismos pueblos por la necesidad imperiosa de conservarse; y no pudiendo hacerlo con buen éxito, sino se organizan de la manera más conveniente... ${ }^{15}$

En lugar de la doble línea de presidios propuesta por Zuloaga, Trías establecía una organización en la que las compañias presidiales combatirían la amenaza externa, mientras que los vecinosse cuidaban de la amenaza interna. Casi sobra decir que la amenaza "externa" resultaba ser la del vecino país. La "interna" era la de los indios.

En octubre de 1845 el gobernador Trías informaba sobre el levantamiento de un grupo de tarahumaras de Satevó que protestaban por la destrucción de sembradíos de tabaco macuchi. Señalaba que había tenido que recurrir a Juan Terrazas, quien "...con todo el empeño y eficacia propios de su carácter alistó con

${ }^{15}$ AGN, 1845, 290, 1. toda prontitud las partidas de vecinos que componen la mayor parte de esa sección para pacificarlos" ${ }^{16}$

La pobreza del erario público agobiaba al gobiernolocal. A principios de 1845 la Asamblea Departamental se dirigía al Ministerio de Relaciones. Después de agradecer la decisión del supremo gobierno de enviar tropas para combatir a los bárbaros, el órgano legislativo señalaba:

Uno de los mayores males que pudieran hacérsele [al departamento de Chihuahua] sería remitirle cuerpos del ejército para hacer la guerra a los indios... Bastará el que el supremo gobierno redoble sus esfuerzos para mandar recursos pecuniarios a fin de aumentar las compañías que actualmente se hallan sobre las armas, y con sólo esto se afianzará la paz y tranquilidad de Chihuahua, sin necesidad de emprender los grandes gastos que demanda la remisión de tropa... En este departamento hay gente bastante para poner sobre las armas... [Están] acostumbrados los hombres desde chicos a sufrir las invasiones de los indios y después a perseguirlos, conocen sus tácticas y sus terrenos. ${ }^{17}$

Es probable que la misiva de los legisladores tuviera también motivos políticos, encaminados tal vez a evitar la presencia de un crecido número de fuerzas

${ }^{16} \mathrm{AGN}, 1845,300,15$ : carta de Angel Trías de 3 de octubre de 1845. En este lugar se hallan varios documentos sobre el levantamiento, incluida una descripción de las posiciones de defensa de los tarahumaras y los movimientos de las tropas de Terrazas, así como sobre las negociaciones que evitaron a final de cuentas el choque armado. En tiempos de García Conde se había reprimido un movimiento tarahumara encabezado por Trinidad Granado, quien tenía la pretensión de proclamarse virrey de tarahumaras y tepehuanes. Almada, $R e$ sumen, 1986, p. 212.

${ }^{17}$ AGN, 1845, 283, 8: carta de 8 de febrero de 1845 . 
del gobiemo general que pudiera desequilibrar la política local.

\section{LOS "BÁRBAROS" COMO ARGUMENTO POLITTCO}

Un asunto tan candente como la amenaza india no podia quedar fuera del discurso político, ni de los esfuerzos para consolidar distintas posiciones políticas.

Un ejemplo de ello lo ofrece el propio general Monterde, quien no parecía desconocer la importancia de las campañas contra los nómadas, sobre todo en términos de su prestigio como gobernante. En la misma carta de marzo de 1843 el entonces gobernador del departamento señalaba:

Además de otras providencias que he dictado en otros ramos de las que daré cuenta a V.E. cuando haya concluido mi visita a la vez que manifieste minuciosamente los resultados de ella, por ahora sólo he querido reseñar lo más preciso con respecto a indios que es el objeto de expectación para los chihuahuenses, y el que debe ocupar con preferencia a este gobierno, como que de la solidez de las paces celebradas con los bárbaros depende la felicidad de este departamento.

La amenaza india también servía para combatir enemigos mediante una maniobra que apuntaba a lograr la unidad chihuahuense a toda costa dada la magnitud de aquella amenaza. Vale abundar sobre esta idea.

Atrás se mencionó que García Conde había gozado de gran popularidad, ventaja de la que carecerían sus sucesores, Monterde y Zuloaga. La destitución de García Conde a fines de 1842 y el subsiguiente arribo de Monterde crearían

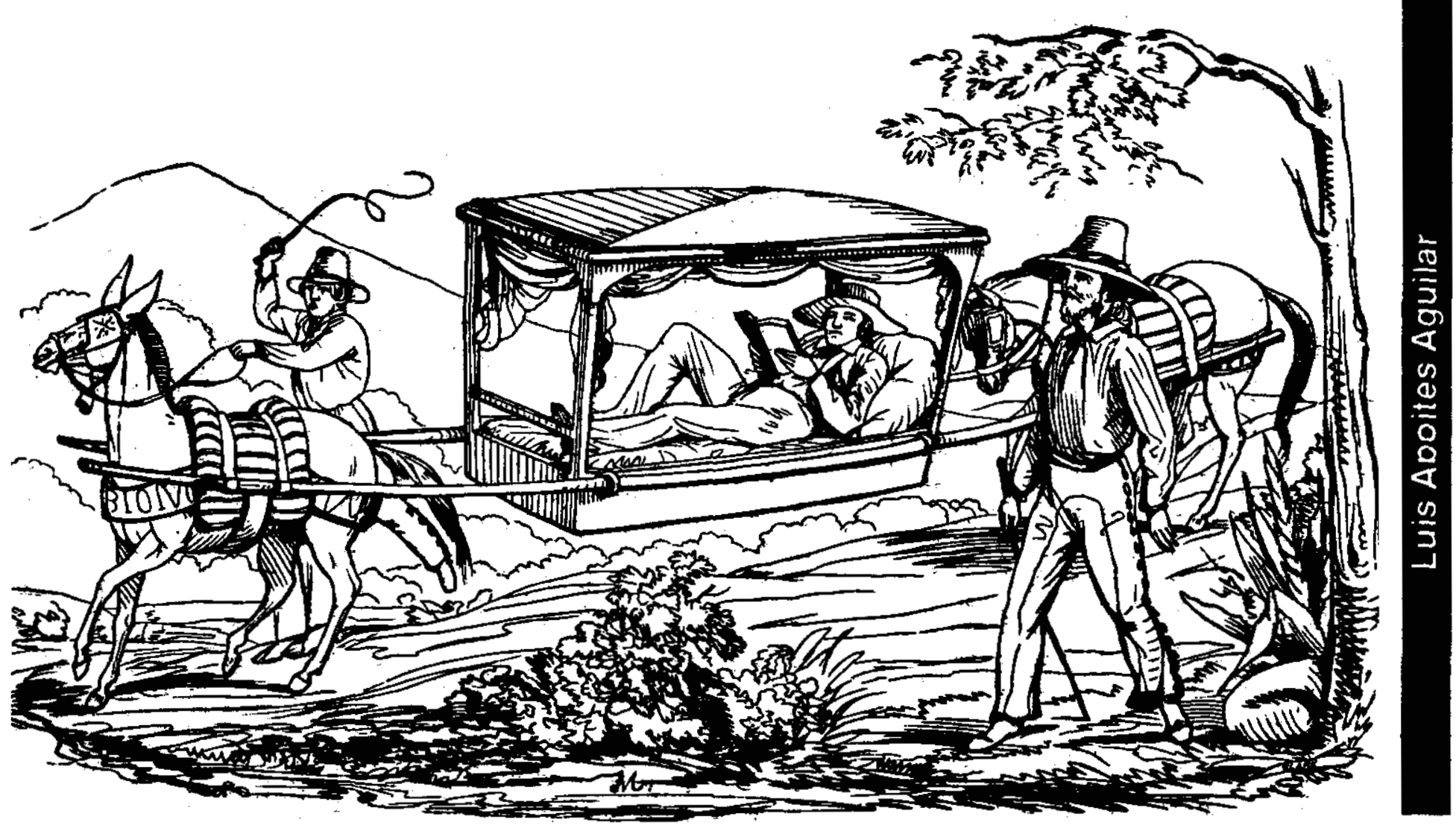


una profunda división política en la elite local. Esa división se agravaría a lo largo de la segunda mitad de 1843 y durante todo el año de 1844. A fines de este año, en el marco del pronunciamiento de Mariano Paredes y Arrillaga en Guadalajara, algunas personas, incluyendo militares del presidio de Paso del Norte, se habían expresado en contra del gobierno de Monterde y a favor de Paredes. El diario del gobierno local, la Revista Oficial, expresaba lo siguiente:

Entodos los movimientos revolucionarios que desgraciadamente han tenido lugar en la república, desde su gloriosa emancipación, Chihuahua había conservado una posición pacífica, jamás se había movido si no era para prestar obediencia a las supremas autoridades. El castigo del salvaje habia sido el único objetode atención de sus habitantes. ${ }^{18}$

Como la rebelión parecía crecer, el gobernador no dudaría en recurrir al argumento de la guerra contra los nómadas como imperativo supremo del interés general:

El que os habla no quiere que en el departamento de Chihuahua se oiga el estruendo del cañón si no es para el exterminio del salvaje, como tampoco quiere ver mutilado a un solo chihuahuense, ni ver correr las lágrimas del huérfano y dela viuda, efectos necesarios de la guerra civil. ${ }^{19}$

A principios de enero de 1845 Monterde volvía a dirigirse a sus gobernados:

Unámonos: [que] la guerra a los salvajes y a los tejanos sus aliados sea nuestro único

${ }^{18}$ El Siglo XIX, 13 de enero de 1845.

${ }^{19}$ Archivo Histórico Militar de México, Fondo Siglo XIX, exp. xl/481.3/2048, ff. 10-11: proclama de Monterde de 9 de diciembre de 1844 dirigida a los habitantes de Paso del Norte. objeto; y al echar un velo sobre lo pasado y sobre nuestros errores, consideremos que el destino de Chihuahua es seguir la mayoría de la opinión nacional, y que cuando ésta no es conocida, debe obedecer a las autoridades supremas. ${ }^{20}$

En pocas palabras, Monterde llamaba a dejar las diferencias políticas al margen y concentrar la atención en la guerra dela frontera. El argumento no sería escuchado por sus enemigos, como se verá más adelante.

En diciembre de 1844 Monterde se defendía, ante el ministro de Relaciones, de aquellos "que se han puesto por sí y ante si el nombre de liberales". Al refutar uno de los tantos cargos, Monterde señalaba:

Dicen mis detractores que yo soy el origen de todos los males que sufre Chihuahua. Este cargo tan vago, se refuta por símismo, si se atiende que yo no puedo ser la causa dela enfermedad, de las incursiones delos bárbaros, ni de otros males que sufre Chihuahaua. ${ }^{21}$

Los indios también podían servir de pretexto para encubrir presuntas maniobras de los enemigos del gobierno supremo. En agosto de 1844, al referirse a una invasión sonorense que será tratada más adelante, Monterde informaba al Ministerio de Relaciones:

Los partidarios enemigos del actual orden de cosas que existen en este departamento no pierden ocasión para llevar adelante sus ambiciosas miras, y tal vez con ellas tiene relación el movimiento de Sonora, pues hace algún tiempo que se me había anticipado, dejándose correr en esta ciudad y en algunos pueblos del depar-

${ }^{20}$ El Siglo XIX, 28 de enero de 1845.

${ }^{21}$ AGN, 1844, 282, 2: carta de 21 de diciembre de 1844 de Monterde al ministro de Relaciones . 


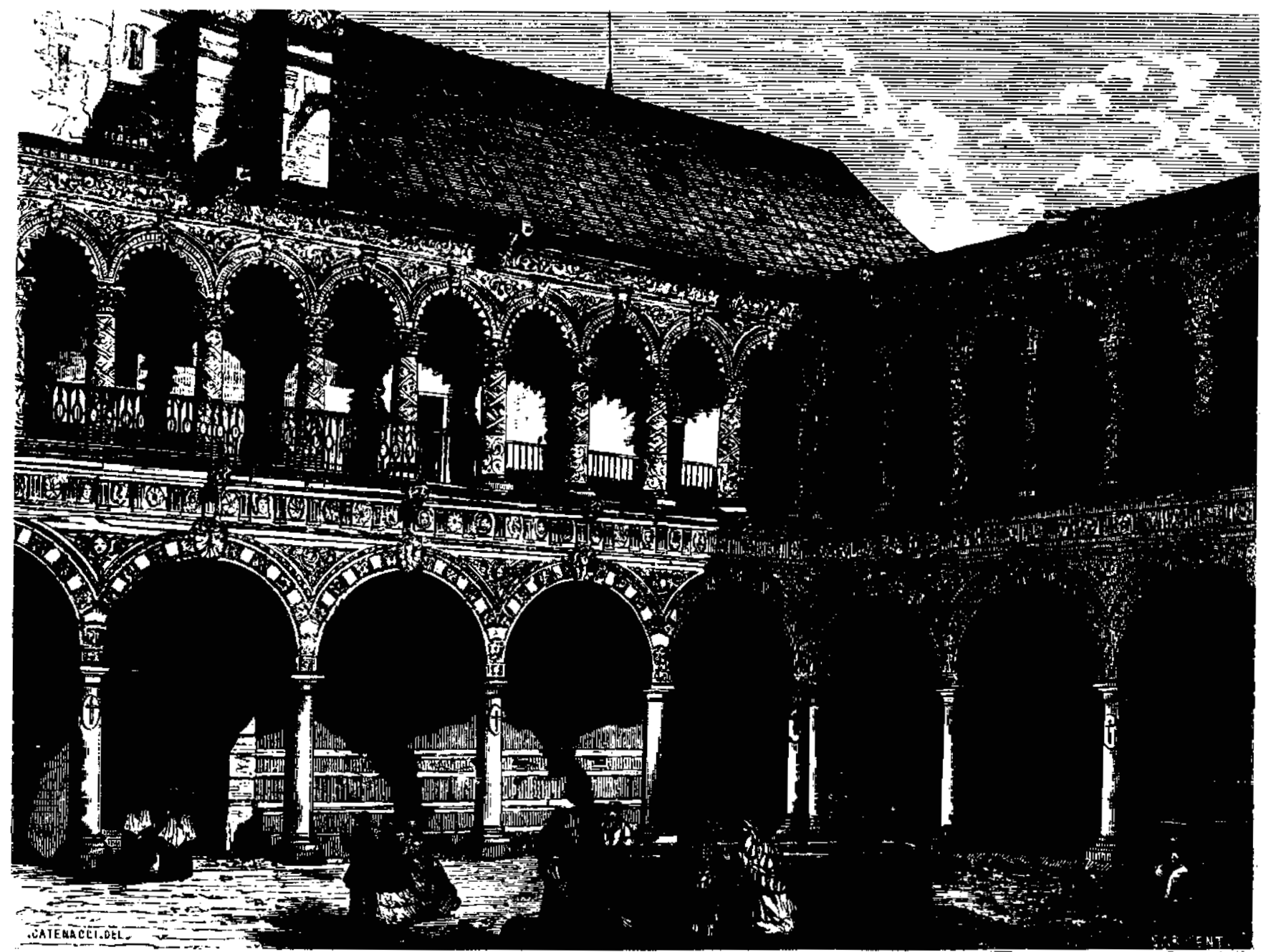

tamento, las especies de que Sonora por medio del general Urrea sostendría sus miras, pronunciándose por la federación las fuerżas que en el número que lo han hecho, debían invadir este departamento, bajo el pretexto de batir a los indios. ${ }^{22}$

En la polémica de 1852 referida atrás, Cordero negaba haber ofrecido su fortuna personal para la guerra con los indios y señalaba que eso hubiera sido “...ridículo para prometido, y estúpido y necio para creído...". En esa ocasión el riquísimo gobernante señalaba:

Tampoco me avergüenzo ante el estado de Chihuahua por la imputación que se me ha hechode haber faltado a las promesas, que dizque hice, de invertir mi fortuna en la guerra con los indios. Loque me pro-

\footnotetext{
${ }^{22}$ AGN 1844,282 , 4: carta de Monterde de 29 de agosto de 1844 .
}

puse fue ayudar con mis propios recursos, con el prestigio de mis relaciones, y con un peculiar y decidido empeño, a los medios de que pudiera disponer el poder que se me confiaba.

Como se puede ver, la aclaración de Cordero no resulta del todo convincente pues deja ver que efectivamente prometió utilizar sus propios recursos para sostener la guerra contra los nómadas.

\section{UNA REBELIÓN CIVIL: UN GOBIERNO SIN EJERCITO}

Sin el apoyo del gobierno general, que en diciembre había cambiado de las manos de Vicente Canalizo a las de José Joaquín Herrera, Monterde caería de su alta posición política y militar en la segunda mitad de enero de 1845. Sería reemplazado en el cargo de gobernador 
por el diputado Luis Zuloaga. ${ }^{23}$ Pero el cambio no apaciguaría la profunda división política local. El desenlace de esta pugna a mediados de año proporciona elementos para explorar otra dimensión del problema de este trabajo.

El arribo de Zuloaga a la gubernatura no tranquilizaría los ánimos. Al hermano de Félix se le identificaba como el líder de la facción política local que había pactado con el general Monterde. Desde meses atrás se le consideraba incluso como el poder tras el trono. ${ }^{24}$ Con esos antecedentes no es dificil entender la persistencia del conflicto.

En la primera semana de junio los acontecimientos se precipitaron en contra de Zuloaga ${ }^{25}$ Un testigo recordaría la situación de esos días:

Desde el 9 del corriente comenzaron a correr rumores de que en varios puntos no muy distantes de esta capital se armaban muchos ciudadanos y se preparaban para dirigirse sobre ella con el objeto de deponer a las autoridades superiores: dos días después nadie lo dudaba ya, y fue tal la agitación que comenzó a sentirse en esta ciudad, que yo no recuerdo haber visto otra mayor en más de $\mathbf{4 0}$ años que llevo de vida. ${ }^{26}$

${ }^{23}$ El Siglo $X D X, 7$ de febrero de 1845.

${ }^{24} \mathrm{AGN}, 1844,282,2$ : carta de 27 de agosto de 1844 dirigida al presidente de la república. Firmaban entre otros Angel Trías, Bernardo Revilla, Manuel Muñoz, Mariano Maceyra y Laureano Muñoz.

${ }^{25}$ Inútilmente la Legislatura local derogó por esos dias una impopular ley de julio de 1843 que establecía impuestos al comercio de carbón, frijol, leña y toda clase de semillas, legumbres y frutas. En los considerandos podía leerse que "por la inseguridad de los caminos del departamento a causa de los bárbaros" se aumentaban los costos y que ello "arruina[ba] a la agricultura y se perjudicalbal enorme y preferentemente a los labradores pobres y consumidores". AGN, 1845, 290, 1: decreto de 7 de junio de 1845.

${ }^{26}$ Informe del gobernador interino Joaquín
Los rumores fueron efectivamente ciertos porque en la noche del 12 de junio el gobernador Zuloaga firmaba con los líderes alzados un acuerdo que entre otras cosas contenía su renuncia y la de otros destacados partidarios del gobernador y del general Monterde. ${ }^{27} \mathrm{La}$ capital departamental estaba sitiada por los alzados, poco más de 2000 hombres armados.

Hay dos hechos interesantes en este levantamiento armado, en el que la sangre no llegó al río. El primero fue que los rebeldes habían organizado la fuerza armada con vecinos, parientes, trabajadores, es decir, se trataba de una fuerza militar compuesta por civiles. ${ }^{28} \mathrm{El}$ segundo hecho es que el ejército se había retirado de la contienda el 11 de junio en el marco de un distanciamiento entre el gobernador Zuloaga y el comandante, coronel Justiniani. ${ }^{29}$ Sin ningún mapoyo militar, Zuloaga parece haber actuado con sensatez al acceder al arreglo pacífico.

En este caso la actitud del ejército -el retiro de su respaldo al gobernadorpuede ser más indicativo de las difíciles relaciones entre el poder civil y el militar que se traducían en inestabilidad guber-

Bustamante de 20 de junio. El Siglo $X I X, 14$ de juiio de 1845.

${ }^{27}$ El texto completo de este acuerdo fue publicado en la ciudad de México por El Siglo XIX de 4 de julio de 1845.

${ }^{28}$ En la edición de 14 de julio de 1845 el diario El Siglo XIX publicó una generosa crónica del levantamiento. Incluye los nombres de los principales jefes y sus zonas de influencia y reclutamiento. En esa ocasión Cordero organizó a un grupo de voluntarios a sus expensas en su lugar de origen, el valle de San Bartolomé.

${ }^{29}$ El texto de la carta de Justiniani a Zuloaga se reproduce en El Siglo XIX del 22 de julio de 1845. El coronel alegaba no apoyar a los liberales, es decir, los enemigos de Zuloaga. Y expresaba su obediencia al recién nombrado jefe dela 5 a. división militar, ni más ni menos que don Francisco García Conde. 
namental, o del impacto local de pugnas políticas de nivel nacional. Sin embargo, no puede descartarse tan fácilmente la capacidad de convocatoria y reclutamiento de los enemigos de un gobernante que se veía de pronto sin fuerzas bajo su mando para enfrentar el levantamiento. De esa manera, a la debilidad represiva del ejército parecía sumarse su independencia o autonomía con respecto al gobierno. En ambos casos, los particulares hallaban grandes espacios para su intervención.

\section{LA PRECARIEDAD DEL TERRITORIO}

Las dificultades del poder público anotadas antes se traducían en un frágil control sobre el territorio. Este era un rasgo sobresaliente de la situación del septentrión entero en estos años. El problema, sin embargo, no se reducía al Estado. Los grupos sociales también se veían afectados severamente por la incapacidad social de enfrentar las amenazas territoriales que les imponían por igual nómadas y estadunidenses.

Un problema de fondo era la escasa población, el desierto propiamente dicho. García Conde señalaba en agosto de 1842 que "... los indios son invencibles, si con abundantes recursos, no se cuenta además con una población numerosa y convenientemente repartida, o con algunos aliados de ellos mismos". El gobernadorZuloaga lo planteaba de otro modo: "...tan escasa población hace que el departamento en la mayor parte de sus terrenos sea un verdadero desierto, y que los bárbaros se encuentren viviendo en ellos sin obstáculo alguno". ${ }^{30}$ Para col1845. mo, la población del departamento, que se calculaba en unos 145000 habitantes hacia 1838 , había disminuido su ritmo de crecimiento por lo menos desde $1831 .^{31}$ El desierto facilitaba, como indicaban estos personajes, la movilidad de los nómadas, pero también el contrabando, el comercio ilegal con los indios y las amenazas de texanos y estadunidenses.

Sin embargo, como se ha mencionado, este desierto era distinto al de unos años atrás, toda vez que los texanos y estadunidenses en general habian "corrido sus líneas" hacia esta porción y con ellos los indios apaches y comanches. Por lo pronto era una zona de fuertes intercambios comerciales, las más de las veces fuera del control gubernamental. En ese sentido, más que desierto era una vasta extensión de tierra ocupada y controlada por los indios, lo que inhibía el poblamiento con vecinos chihuahuenses. ${ }^{32} \mathrm{Re}$ cuérdese que en la carta de 8 de febrero de 1845 citada antes, la Asamblea Departamental indicaba que "hay gente bastante para poner sobre las armas". Entonces, la escasa población, o se usaba de manera interesada, o bien se refería a su forma de distribución en el territorio, como señalaba García Conde. De cualquier manera el poblamiento se manejaba como elemento imprescindible

${ }^{31}$ En 1831 la población se estimaba en 139129 yen 164063 en 1857. Para tener forma de comparación cabe decir que hacia 1800 Gerhard calcula en 80600 la población de los pueblos de la Nueva Vizcaya que luego serían parte de Chihuahua. A partir de aquí se puede ofrecer una comparación de tasas de crecimiento medio anual de: 1.77 en el periodo 1800-33, a 0.67 en el de 1831-57. Gerhard, The north, 1982, pp. 170-171; Almada, Diccionario, s. f., p. 98.

${ }^{32}$ Un estudioso cita el hecho de que los apaches llegaron a cobrar impuestos a las personas que viajaban entre Nuevo México y Sonora. Weber, $\mathrm{La}$ frontera, 1988, p. 133. 
para mejorar la defensa y en general la situación local. En su propuesta ya mencionada sobre la línea doble de presidios, Zuloaga apuntaba una ventaja adicional:

Además, el establecimiento de presidios producirá con el tiempo la formación de poblaciones en los terrenos que hoy se encuentran desiertos, resultando de aquí todas las ventajas que son consiguientes a la población ya no sólo para la mejor defensa contra el salvaje sino para la agricultura cuyo ramo no es el menos interesante de este departamento aun cuando la minería es la que forma su riqueza en lo general. ${ }^{33}$

Otro aspecto era la ignorancia sobre algo tan importante como la tenencia de la tierra. Cuando informaba de sus gestiones ante los vecinos de San Buenaventura para obtener en préstamo tierras agrícolas, el gobernador Monterde explicaba que dicha solicitud obedecía a que carecía "...aun de los datos necesarios sobre los terrenos baldíos de que se pueden echar mano para repartir a los indios". ${ }^{34}$ Tal ignorancia no debía resultar extraña, toda vez que el mismo gobierno general la compartía puntualmente. ${ }^{35}$

Como se ha visto, uno de los principales medios para contrarrestar los ataques de los nómadas era la firma de tratados de paz con algunos grupos. Sin embargo, estos tratados o convenios parecían tener una grave desventaja, la cual se desprendía a final de cuentas del escaso control que tenían las autoridades gubernamentales sobre el territorio. Dicha desventaja se refería a la práctica de

${ }^{33}$ AGN, 1845, 282, 8: carta de Luis Zuloaga de 29 de marzo de 1845 .

${ }^{34}$ AGN, 1843, 265, 5.

${ }^{35}$ Memoria, 1857, p. 38.

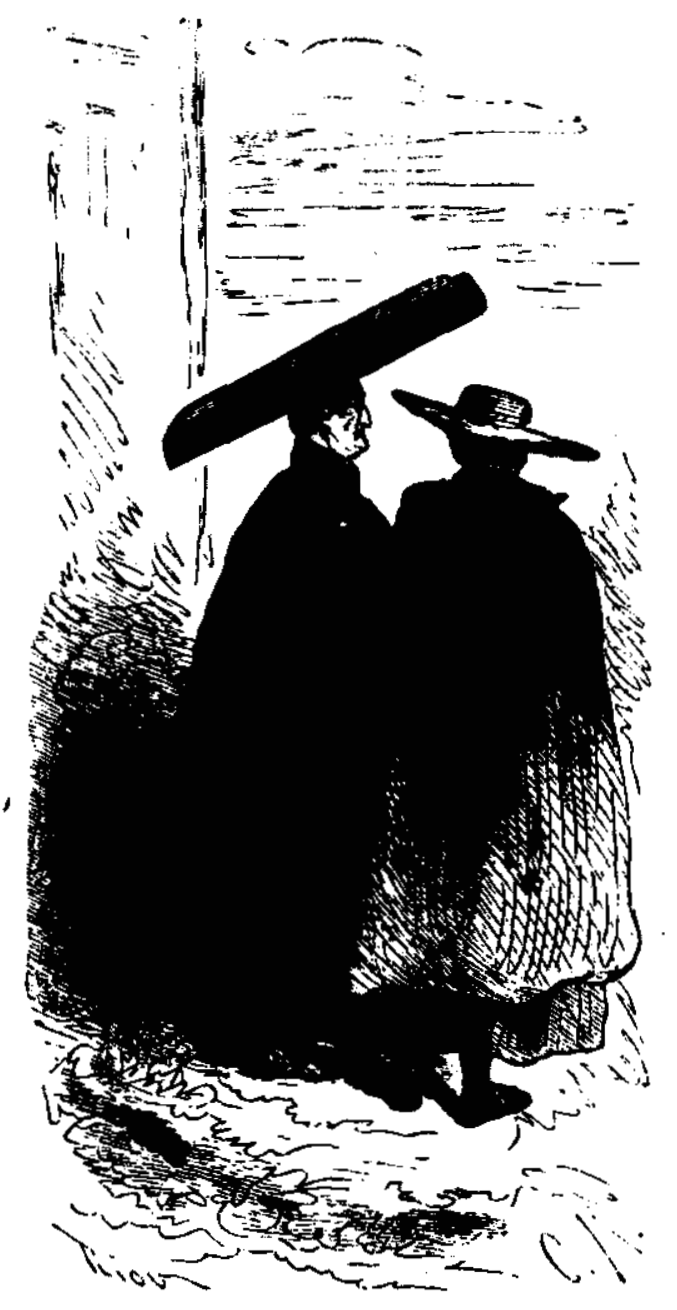

los apaches de manipular los acuerdos de paz para conseguir una zona donde refugiarse después de realizar sus ataques en otros lugares.

Esta táctica saldría a la luz a mediados de 1844 cuando una fuerza sonorense de 800 hombres atacó un campamento de apaches pacíficossituado junto al presidio de Janos. Resultaron once indios muertos y cinco prisioneros. Furibundo porque el ataque sonorense ponía en peligro la paz de Chihuahua, Monterde insinuó que si era necesario expulsaría por la fuerza al destacamento del departamento vecino. Los sonorenses, por su parte, argüían que los apaches de Janos eran los responsables de los robos y crímenes ocurridos cerca del presidio de Santa Cruz. ${ }^{36}$

\section{Santa Cruz.}


Los tratados celebrados en Chihuahua no eran bien vistos en otros lugares. En 1843 el presbítero de Taos, Antonio José Martínez, se refería con ironía a la "compra de paz", que significaba "...perder el honor de nuestras armas", además de que degradaba a los chihuahuenses. ${ }^{37} \mathrm{En}$ febrero de 1845 un duranguense anónimo veía publicada una carta suya en un diario de la capital del país. En ella calificaba de ominosos e inmorales los tratados de los chihuahuenses con los indios. Recogía las opiniones de algunos observadores que señalaban que los indios hacían la paz con un departamento para atacar a otros. Por ello el anónimo duranguense explicaba (y en cierto modo justificaba) la invasión sonorense a Chihuahua en agosto del año anterior. ${ }^{38}$

Esta cuestión territorial no era problema exclusivo de un solo departamento. La carencia de un mando centralizado a nivel nacional parecía traducirse en esfuerzos aislados que resultaban contraproducentes para entidades cir-

tido dinero y otros útiles para dar confianza a los apaches que aún no recibían ataques sonorenses. Ello había agravado la escasez de recursos del gobierno, pues la renta de tabaco carecía de fondos por los pagos efectuados a los individuos que prestaron dinero en ocasión de la expedición a Nuevo México del año anterior.

37 "Exposición que el presbítero Antonio José Martínez , cura de Taos en Nuevo México dirije al gobierno del Exmo. señor general don Antonio López de Santa Anna, proponiendo la civilización de las naciones barbaras que son al contorno del departamento de Nuevo México", reproducido en Weber (comp.), Northern, 1976.

${ }^{38}$ El Siglo XIX, 8 de enero de 1845 . No sobra decir que desde fines de 1844 el departamento de Durango padecia grandes incursiones de comanches, que llegaban hasta 20 leguas de la capital, según informaba Alejo García Conde, comandante militar, en una nota escrita en la navidad de 1844 , ver El Siglo XIX, 13 de enero de 1845. Alejo era hermano mayor de Francisco y de Pedro. cunvecinas. Tal vez por ello, y porque el gobierno general se mostraba incapaz de asumir esa responsabilidad, varias entidades norteñas intentarían formar coaliciones en los años subsiguientes. Tal vez por este mismo problema los estadunidenses no hallaron gran resistencia de parte de las desorganizadas provincias del septentrión mexicano en la guerra de 1846-48. Otro capítulo se abre precisamente con los detalles de los esfuerzos locales para enfrentar la invasión estadunidense. ${ }^{39}$

Después de la guerra el panorama no mostraba mejoría. A principios de 1849 Angel Trías se dirigía a la Legislatura local:

Nuestro estado, puede decirse que es hoy un vasto desierto, en donde se hallan esparcidas algunas pequeñas y miserables poblaciones, las que no tienen seguridad, ni bienestar sus habitantes; y a pesar de que la naturaleza ha prodigado a nuestro suelo abundantes riquezas y poderosos elementos de prosperidad, apenas se han entendido en nuestra sociedad, porque la civilización se halla en su cuna y nuestra población es por demás diminuta. ¿Dequé nos sirven tantos dones con que la Divina Providencia ha colmado nuestro país, sila industria es apenas conocida; si la agricultura gime bajo la ferocidad de los salvajes; si nuestro comercio no tiene la menor seguridad para sus giros; si la minería se halla paralizada, si nuestra población es tan escasa que toda la que tiene el estado diseminada en una área de más de 16000 leguas cuadradas, podría contenerse en una ciudad de tercer orden?

39 Uno de ellos es que el gobernador Trías aportó "fuertes cantidades" de su fortuna personal en los preparativos de la defensa de Chihuahua. Almada, Gobernadones, 1950, p. 129.

40 "Contestación del Excmo. señor gobernador C. Angel Trías", de 20 de febrerode 1849, en Muñoz (comp.), Informes, 1910, p. 8. 
COMO EPILIOGO

En noviembre de 1847 la Legislatura chihuahuense protestaba ante la inminente firma de un tratado de límites con Estados Unidos. Una parte de esa exposición se refería al problema de los nómadas. El órgano legislativo condicionaba la firma del tratado a que

...Estados Unidos se comprometa expresamente con suficientes garantías, a no favorecer directa ni indirectamente la invasión de dichas tribus sobre nuestras fronteras, y que al efecto, se obligue a que ni sus gobiernos ni sus nacionales, ni sus indios, ni habitante alguno de aquella república, comprará los robos que los salvajes hacen en la nuestra, ni los proveerán de armas ni municiones. ${ }^{4 l}$

La situación de los chihuahuenses en relación con los nómadas tenía que ver cada vez más con los estadunidenses, con su avance sobre el suroeste de su territorio. Así había ocurrido por lo menos desde 30 años atrás. La formación de una nueva frontera modificaría las condiciones del esfuerzo local por constituir un sólido aparato estatal. Lo cierto es que ese esfuerzo seguiría teniendo escasos frutos si no se acompañaba del fortalecimiento del gobierno general. En 1848 éste intentaría dar una respuesta a través de la formación de colonias militares. Pero el fracaso de este intento desembocaría, hacia 1851 y 1852 , en las iniciativas de gobiernos locales para formar coaliciones de estados contra los indios nómadas. En el caso de la coalición de 1852 se decía enfáticamente que esa organización desaparecería cuando el supre-

${ }^{41}$ Archivo de la Secretaría de Relaciones Exteriores, LE-1088, f. 140: copia de 7 de diciembre de 1847. mo gobierno defendiera eficazmente la frontera. ${ }^{42}$ En Chihuahua por lo pronto se volvería a recurrir a los particulares para enfrentar la amenaza apache. En mayo de 1849 la Legislatura facultaba al ejecutivo para contratar a nacionales y extranjeros con tal objeto y fijaba un pago de 150 pesos por indio muerto y 25 por indio prisionero. ${ }^{43}$ Tendrían que pasar décadas para que el poder público fuera capaz de imponer efectivamente la tranquilidad y la obedencia en esta tierra del septentrión. Y en esa tarea Estados Unidos tendría su papel.

Lo que interesa destacar es que la amenaza de los "bárbaros" expresaba un inacabado fortalecimiento del poder público y ello a su vez provocaba un difícil deslinde entre ese poder y los particulares. Éste puede ser acaso un esbozo de una forma de aproximación desde el norte del país al tema tan socorrido de la inestabilidad política del siglo XIX. Esta aproximación probablemente brindará evidencia novedosa para retomar esa temática con una perspectiva que puede llegar a ser refrescante.

Por último, el énfasis en la amenaza india no debe llevar a considerarla como el elemento medular de los procesos sociales en Chihuahua y en general en el norte en esta época. Como se intentó mostrar, los vecinos se daban tiempo para enriquecerse, para pelear por el control del débil aparato político, para enemistarse, para aplastar protestas tarahumaras y hasta para defenderse de texanos y estadunidenses. Lo único es

42 González Navarro, Anatomía, 1983, p. 61.

${ }^{43}$ Almada, Resumen, 1986, p. 235. En realidad desde junio de 1846 el gobierno local había recurrido una vez más al "aventurero" Kirker. Este personaje se uniria a las tropas estadunidenses en febrero siguiente. 
que ese problema resulta inevitable y por lo mismo no parece descabellado explorar una forma de estudiarlo.

Como se ha intentado mostrar, esa forma consiste en ubicar a los "bárbaros" en términos de un proceso histórico más amplio y complejo como es el de la conformación del Estado y el territorio. En ese sentido, se trata de mostrar las ventajas de abrir la perspectiva de estudio y relacionar la beligerancia india con otros componentes de la vida social. Sin duda, este "problema indio" amerita una atención cuidadosa y sostenida. Pero de nuevo, la necesaria especialización temática que exige la gran cantidad de material disponible no debellevar a ignorar que en la historia de los bárbaros estaban entretejidas muchas historias más.

\section{BIBLIOGRAFÍA}

-Almada, Francisco R., Diccionario de bistoria, geografia y biografia chibuabuenses, Centro Librero "La Prensa", Chihuahua, s.f.

- Gobernadores del estado de Chibuabua, Imprenta de la H. Cámara de Diputados, México, 1950.

-Resumen de bistoria del estado de Cbibuabua, Gobiemo del Estado, Chihuahua, 1986.

-Altamirano, Graziella y Guadalupe Villa (comps.), Chibuabua. Textos de su bistoria 1824-1921, Instituto de Investigaciones Dr. José María Luis Mora/Gobierno del Estado de
Chihuahua/Universidad Autónoma de Ciudad Juárez, México, 1988, vol. III.

-Gerhard, Peter, The north frontier of New Spain, Princeton University Press, Princeton, 1982.

-González Navarro, Moisés, Anatomía del poder en México 1848-1853, El Colegio de México, México, 1983.

-Informe de la comisión pesquisidora de la frontera norte al ejecutivo de la Unión sobre depredaciones de los indios $y$ otros males que sufre la frontera mexicana, Imprenta del Gobierno, México, 1877.

-Memoria del Ministerio de Fomento, Colonización, Industria y Comercio de la república mexicana, escrita por el ministro del ramo C. Manuel Siliceo, Imprenta de Vicente García Torres, México, 1857.

-Muñoz, Francisco A., (comp.), Informes que los gobermadores del estado de Chibuabua ban presentado ante el Congreso del mismo desde el año de 1849 basta el de 1906, Imprenta del Gobierno, Chihuahua, 1910.

-Ponce de León, José María, Reseña bistórica del estado de Chibuabua, Tipográfica de la Escuela de Artes y Oficios, Chihuahua, 1905.

-Vázquez, Josefina Z. y Lorenzo Meyer, México frente a Estados Unidos (un ensayo bistórico 1776-1988), Fondo de Cultura Económica, México, 1989.

-Weber, David J., La frontera norte de México 1821-1846. El sudoeste norteamericano en su época mexicana, Fondo de Cultura Económica, México, 1988. (comp.), Northerm Mexico on the eve of the United States invasion, Arno Press, New York, 1976. 